\title{
INTEGRATING PREVENTIVE MAINTENANCE SCHEDULING AS PROBABILITY MACHINE FAILURE AND BATCH PRODUCTION SCHEDULING
}

\author{
Zahedi $^{1}$; Ashadi Salim² \\ ${ }^{1,2}$ Mathematics and Statistics Department, School of Computer Science, Bina Nusantara University \\ Jln. K.H. Syahdan No. 9 Palmerah, Jakarta Barat, 11480 \\ ${ }^{1}$ zahedizahedi@binus.ac.id; ${ }^{2}$ ashadisalim@binus.ac.id
}

\begin{abstract}
This paper discusses integrated model of batch production scheduling and machine maintenance scheduling. Batch production scheduling uses minimize total actual flow time criteria and machine maintenance scheduling uses the probability of machine failure based on Weibull distribution. The model assumed no nonconforming parts in a planning horizon. The model shows an increase in the number of the batch (length of production run) up to a certain limit will minimize the total actual flow time. Meanwhile, an increase in the length of production run will implicate an increase in the number of PM. An example was given to show how the model and algorithm work.
\end{abstract}

Keywords: integrated model, batch scheduling, maintenance scheduling, actual flow time, machine failure probability

\section{INTRODUCTION}

The independence of production in scheduling and maintenance scheduling can implicate to several conditions. First, production scheduling that does not pay attention to maintenance aspect will cause the machine continues to be used, even though the machine has to be for maintenance. If maintenance is not done, it will result in machine break down, so it will interfere production scheduling. Second, the maintenance activities do not pay attention to the production. Thus, the busy machine must be stopped for maintenance. This will interfere the production schedules that have been prepared previously.

Research that integrate batch scheduling on one machine with probabilistic maintenance time determined by the optimization method as Lee and Rosenblat (1987), Wang and Sheu (2001), Tseng (1996), Ben-Daya and Noman (2006), Lin and Hou (2005), Chelbi et al. (2008), Makhdoum (1996), El-Ferric and Ben-Daya (2010) as well as Zahedi (2013). Lee and Rosenblat (1987) discussed the problem of joint control of the production cycle and maintenance scheduling as inspection of parts from the machine. This study developed a relationship between maintenance and inspection showed that the optimal inspection interval is equally-spaced. Simultaneous solution of the model is a lot EMQ and schedule inspections are completed with the cost function approach.

Wang and Sheu (2001) developed an integrated model to determine the lot size and the optimal inspection policy to minimize the expectations of the average cost per unit of time in the deteriorated production system. The trade-off between production cost and maintenance cost analyzed in this model to get a production lot size and optimal time inspection. Tseng (1996) proposed an optimal policy of preventive maintenance for deteriorated production system. The proposed policy 
model involves the production process that the deterioration status becomes out of control, the number of items defect, and to optimize the cost of failure includes the rework cost and warranty cost.

Ben-Daya and Noman (2006) developed a model that provides integrated decision optimal inventory levels, production run length and preventive maintenance schedule and warranty decisions simultaneously. The criteria are maximizing profit per unit of product, i.e. the expectation value of revenue minus the expectation cost of manufacturing cost, the cost of PM and inspection as well as warranty cost and CM cost. Lin and Hou (2005) studied the determination of the length of the production run for the model EMQ with deteriorated production process and involved the cost of CM. The objective is to find the model of optimal intervals that minimize the total cost per unit of time consisting of setup costs, inventory cost, the cost of CM and rework cost.

Chelbi et al. (2008) proposed a model of determining lot size Q and time T optimal to implement preventive maintenance based on deteriorated production system life cycle. The system criteria are minimizing the average total cost per unit of time by engaging in a machine inventory during the maintenance period. Makhdoum (1996) developed models of integrated maintenance, quantity of production, inspection schedules and design quality control policy that manipulates preventive maintenance activity to be more realistic. An average x control chart is used to monitor the production process, and to earn the effect of maintenance on the quality and quantity of product. Elferric and Ben-Daya (2010) discussed the integration of production and maintenance, where the time required for maintenance and replacement cannot be negligible. Preventive maintenance in the case is imperfect preventive maintenance, where the products can worsen after an imperfect PM. The problem is to find the length of the production run that minimizes the total actual flow time. Zahedi (2013) discussed the integration of batch scheduling and maintenance where machine time maintenance is a proportion of the length of production run with considering a common due date.

This paper proposes the integration batch production scheduling and preventive maintenance (PM) determined by the probability of machine failure. The objective of the model is to minimize the total actual flow time.

\section{METHODS}

Supposed a set of $q$ parts of the same item as an order will be processed on a machine with unavailability machine as the probability of machine failure. Each part requires a process to complete the operation (single stage). The decision variables are number and schedule of batches in each production run, number and schedule of PM. The objective of the model is minimization total actual flow time. The parameters of the model are the processing time per part $t$, setup time between two consecutive batches $s$, the number of parts that will be scheduled $q$, and the time of delivery of the all parts $d$ (a common due date). The machine is a deteriorating machine with Weibull distribution function with probability density function as follows.

$$
f(t)=\alpha \beta(\alpha t)^{\beta-1} \exp (\alpha t)^{\beta-1} \text {, where } \alpha, \beta>0 \text { and } t \geq 0 \text {, }
$$

The cumulative distribution function for an interval $\left(0, p^{\prime}\right)$ is

$$
F\left(t^{\prime}\right)=\int_{0}^{t^{\prime}} f(t) d t=1-\exp \left(-\alpha t^{\prime}\right)^{\beta-1}
$$


From Eq. (2) will be derived $t^{\prime}$ as

$$
t^{\prime}=\frac{\left[\ln \left(1-F\left(t^{\prime}\right)\right]^{\frac{1}{\beta-1}}\right.}{-\alpha}
$$

The preventive maintenance actions will be done if the probability had reached 0.9 . The conceptual model of batch scheduling with minimizing the total actual flow time criteria (Halim, 1993) with two productions runs as Figure (1) below.

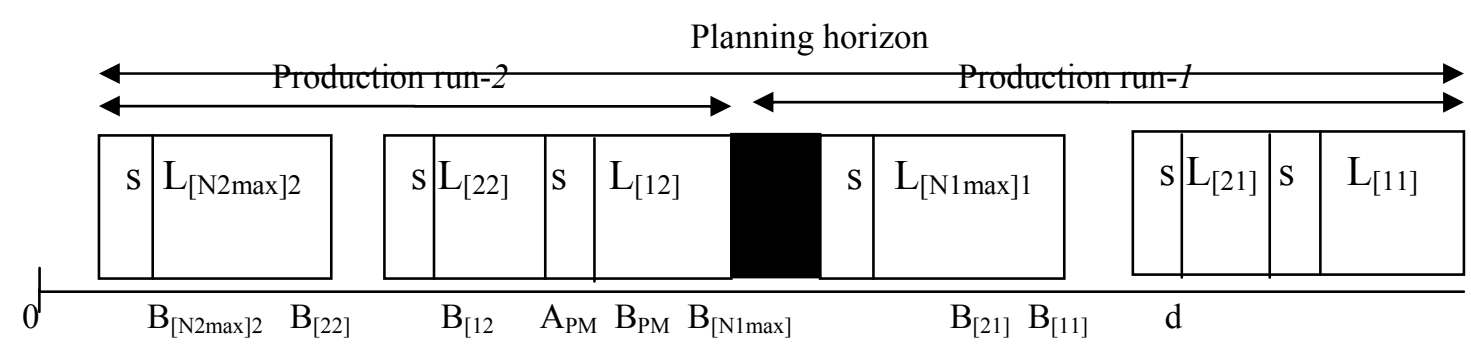

: unavailability machine interval

Figure 1 Gantt-chart Single Item Single Machine with Two Production Runs in Backward Approach

If there is a planning horizon with g-lunavailability intervals of the PM on the machine, then the formulation of total actual flow time can be formulated as follows.

$$
F^{a}=\sum_{k=1}^{g}\left[\sum_{i=1}^{N_{k(\max )}}\left[\sum_{i=1}^{i}\left(s X_{j k}+t Q_{j k}\right)-s\right]+(k-1) t_{P M}\right] Q_{i k}
$$

If there are only two production runs with single unavailability interval of the PM on the machine, then the formulation of total actual flow time is

$$
F^{a}=\sum_{k=1}^{2}\left[\sum_{i=1}^{N_{k(\max )}}\left[\sum_{i=1}^{i}\left(s X_{j k}+t Q_{j k}\right)-s\right]+(k-1) t_{P M}\right] Q_{i k}
$$

$Q_{i k}$ is the number of parts in $i^{\text {th }}$ batch and $k^{\text {th }}$ production run in backward sequencing. $X_{j k}$ is binary variable will be 1 if the batch is not empty and the value 0 if the batch is empty. $t_{\mathrm{PM}}$ is the length of PM time.

Some constraints of the problem can be explained as follow. First, the material balance of parts in all batches scheduled the number of parts in all batches will be equal to the total number of parts that are scheduled, with perfect process without defect parts, 


$$
\sum_{k=1}^{2} \sum_{i=1}^{N_{k(\max )}} Q_{i k}=q
$$

Second, each batch scheduled assumed arrive just in time to be processed in the floor and must be tight to the due date, or it can be written as

$$
B_{i k}+\sum_{l=1}^{k} \sum_{j=1}^{i}\left(s X_{j l}+t Q_{j l}\right)=d, i=1,2, \ldots, N k(\max ) \quad \text { dank }=1,2
$$

Third, for setting the sequencing between batches will be used variable binary $Y_{i j}^{k l}$ that has 0 or 1 value. $Y_{i j}^{k l}=1$ if $i^{\text {th }}$ batch in $j^{\text {th }}$ production run precedes $k^{\text {th }}$ batch in $l^{\text {th }}$ production run in backward sequencing and $Y_{i j}^{k l}=0$ otherwise. For all batches scheduled can be formulated as

$$
B_{i j}+t Q_{i j} \leq B_{(i+1) j}+M Y_{i j}^{(i+1) j}, i=1,2, \ldots,\left(N_{i(\max )}-1\right), j=1,2
$$

Where $M$ is a large number to guarantee sequencing, in practice it can take as $\mathrm{M}=\mathrm{q}(\mathrm{s}+\mathrm{t})$.

Fourth, unavailability interval of machine for the PM along $t_{P M}$ will be in a position as:

$$
\begin{gathered}
t^{\prime}=\frac{\left[\ln \left(1-F\left(t^{\prime}\right)\right]^{\frac{1}{\beta-1}}\right.}{-\alpha} \\
B_{P M}=B_{N 1 \text { (max) }}-s \\
A_{P M}=B_{12}+t Q_{12} \\
B_{P M}=A_{P M}+t_{P M} \\
\sum_{j=1}^{N_{2(\max )}}\left(s X_{j 2}+t Q_{j 2}\right)=t^{\prime}
\end{gathered}
$$

Fifth, the maximum amount of batch is calculated by the equation

$$
\begin{gathered}
\left(N_{(\max )}-1\right) s+t q \leq d, \\
\text { then } \\
N_{\max }=\left[\frac{d-t q}{s}+1\right\rfloor
\end{gathered}
$$


Sixth, there are necessary conditions of the negativity of decision variables and binary variables as follows

$$
\begin{gathered}
Y_{i j}^{k l}+Y_{k l}^{i j}=1 \\
Q_{i j} \geq 0 \\
Q_{i j} \leq X_{i j} q \\
N_{k(\max )} \geq 1
\end{gathered}
$$

\section{RESULTS AND DISCUSSIONS}

Using those constraints and objective function, the integrated batch production and preventive maintenance scheduling as the probability of machine failure to minimize total actual flow time on a deteriorating machine can be expressed as a binary-non-linear programming as follows:

\section{Model}

$$
M I N F^{a}=\sum_{k=1}^{2}\left[\sum_{i=1}^{N_{k(\max )}}\left[\sum_{i=1}^{i}\left(s X_{j k}+t Q_{j k}\right)-s\right]+(k-1) t_{P M}\right] Q_{i k}
$$

\section{Constraints}

$$
\begin{gathered}
\sum_{k=1}^{2} \sum_{i=1}^{N_{k(\max )}} Q_{i k}=q \\
B_{i k}+\sum_{l=1}^{k} \sum_{j=1}^{i}\left(s X_{j l}+t Q_{j l}\right)=d, \quad i=1,2, \ldots, N k(\max ) \quad \text { and } k=1,2 \\
B_{i j}+t Q_{i j} \leq B_{(i+1) j}+M Y_{i j}^{(i+1) j}, i=1,2, \ldots,\left(N_{i(\max )}-1\right), j=1,2 \\
t^{\prime}=\frac{\left[\ln \left(1-F\left(t^{\prime}\right)\right]^{\frac{1}{\beta-1}}\right.}{-\alpha} \\
B_{P M}=B_{N 1(\max )}-s \\
A_{P M}=B_{12}+t Q_{12} \\
B_{P M}=A_{P M}+t_{P M} \\
\sum_{j=1}^{N_{2(\max )}}\left(s X_{j 2}+t Q_{j 2}\right)=t^{\prime} \\
B_{P M}=B_{N 1(\max )}-s
\end{gathered}
$$




$$
\begin{gathered}
\left(N_{(\max )}-1\right) s+t q \leq d \\
Y_{i j}^{k l}+Y_{k l}^{i j}=1 \\
Q_{i j} \geq 0 \\
Q_{i j} \leq X_{i j} \mathrm{q} \\
N_{k(\max )} \geq 1
\end{gathered}
$$

To solve the model, an algorithm to make the model operated is created.

\section{Algorithm}

Step-1. Calculate $\mathrm{T}_{\min }=\mathrm{q} \cdot \mathrm{t}$

Step-2. The problem is feasible if and only if $\mathrm{T}_{\min }+t_{P M} \leq \mathrm{d}$. Go to Step-3. If $\mathrm{T}_{\min }+t_{P M}>\mathrm{d}$ then the problem is infeasible, stop.

Step-3. Calculate $\mathrm{N}_{(\max )}$ by Equation (29).

Step-4. Calculatet'by Equation (24)

Step-5. Substitute values of $\mathrm{N}$ with $\left.\mathrm{N}=\mathrm{LN}_{\max }\right\rfloor, \mathrm{q}, \mathrm{t}, \mathrm{s}, \mathrm{d}, t_{P M}$, and $t^{\prime}$ into the MODEL.

Step-6. Set $Y_{i j}^{k l}=1$, jika ij $<\mathrm{kl}, \forall \mathrm{i}, \mathrm{j}, \mathrm{i} \neq \mathrm{j}$, and $\mathrm{Y}_{\mathrm{i}}^{\mathrm{j}}=0$ otherwise.

Step-7. Set $\mathrm{F}_{11}{ }^{\mathrm{a}}=\mathrm{n}^{2} \mathrm{t}+1$

Step-8. For $\mathrm{i}=1, \mathrm{j}=1$, set $\mathrm{X}_{\mathrm{ij}}=1, \mathrm{i}=1,2, \ldots, \mathrm{N}_{\mathrm{j}(\max )}, \mathrm{j}=1,2$, and $\mathrm{X}_{\mathrm{ij}}=0$ otherwiswe.

Step-9. Set $\mathrm{i}=1, \mathrm{j}=1, \mathrm{k}=1, \mathrm{l}=2, \mathrm{i}=1,2, \ldots, \mathrm{N}_{\mathrm{j}(\max )}, \mathrm{j}=1,2, \mathrm{k}=\mathrm{i}+1, \mathrm{l}=1,2, \ldots, \mathrm{N}_{\mathrm{j}\{\max )}$.

Step-10. Solve Model.

Step-11. Evaluate $\mathrm{B}_{[\mathrm{k}]} \geq 0$,

$$
\begin{aligned}
& \text { - If } \mathrm{B}_{[\mathrm{kl}]} \geq 0, \text { Write } \mathrm{F}_{\mathrm{kl}}{ }^{\mathrm{a}}, \\
& \text { - Evaluate } \mathrm{F}_{\mathrm{kl}}{ }^{\mathrm{a}}<\mathrm{F}_{(\mathrm{k}-1) \mathrm{j}}{ }^{\mathrm{a}}, \\
& \quad-\text { if } \mathrm{F}_{\mathrm{kl}}{ }^{\mathrm{a}}<\mathrm{F}_{(\mathrm{k}-1) \mathrm{j}}{ }^{\mathrm{a}} \text {,setk }=\mathrm{k}+1 \text {, go to step-9. } \\
& - \text { if } \mathrm{F}_{\mathrm{kl}}{ }^{\mathrm{a}} \geq \mathrm{F}_{(\mathrm{k}-1) \mathrm{j}} \text {, go to step-12. } \\
& \text {-If } \mathrm{B}_{[\mathrm{kl}]}<0, \text { go to step-12. }
\end{aligned}
$$

Step-12. Write all values of decision variables and objective function.

The following example would be given to show how the algorithm works.

\section{Example}

Supposed an integrated batch production scheduling and preventive maintenance scheduling as the probability of machine failure with parameters as follows. Number of parts $q=200$, setup time $s$ 
$=30$, processing time $t=20$, preventive maintenance time $t_{P M}=60$, delivery time or due date $d=$ 5000 , a machine with Weibull distribution function with $\beta=1,2$ and $\alpha=0,001$.

\section{Solution}

Step-1 to Step-3 yield $T_{\min }=4000,4000+60<5000$, and $N_{\max }=34$, then the problem is feasible for the model. Step-4 yields $t^{\prime}=\frac{\left[\ln \left(1-F\left(t^{\prime}\right)\right]^{\frac{1}{\beta-1}}\right.}{-\alpha}=2300$. Step-5 to Step-11 yield the best solution. The principle of the steps is an increase in the number of the batch (length of production run) up to a certain limit will minimize the total actual flow time. The best solution is given in Table 1 .

Table 1 The Best Solution for the Example of the Problem

\begin{tabular}{ccccc}
\hline $\boldsymbol{Q}_{i j}$ & $\boldsymbol{B}_{\boldsymbol{i j}}$ & $\boldsymbol{A}_{\boldsymbol{P M}}$ & $\boldsymbol{B}_{\boldsymbol{P M}}$ & $\boldsymbol{F}^{\boldsymbol{a}}$ \\
\hline$Q_{11}=34,3$ & $B_{11}=4313,3$ & & & $472.752,8$ \\
$Q_{21}=32,8$ & $B_{21}=3626,7$ & & & \\
$Q_{31}=31,3$ & $B_{31}=2970,0$ & & & \\
& & 2880,0 & 2940,0 & \\
$Q_{12}=17,8$ & $B_{12}=2534,4$ & & & \\
$Q_{22}=15.8$ & $B_{22}=2188,9$ & & & \\
$Q_{32}=14,3$ & $B_{32}=1873,3$ & & & \\
$Q_{42}=12,8$ & $B_{42}=1587,8$ & & & \\
$Q_{52}=11,3$ & $B_{52}=1332,2$ & & & \\
$Q_{62}=9,8$ & $B_{62}=1106,7$ & & & \\
$Q_{72}=8,3$ & $B_{72}=911,1$ & & & \\
$Q_{82}=6,8$ & $B_{82}=745,6$ & & & \\
$Q_{92}=5,3$ & $B_{92}=610,0$ & & & \\
\hline
\end{tabular}

The best solution in Gantt-chart is given in Figure 2 as follows.

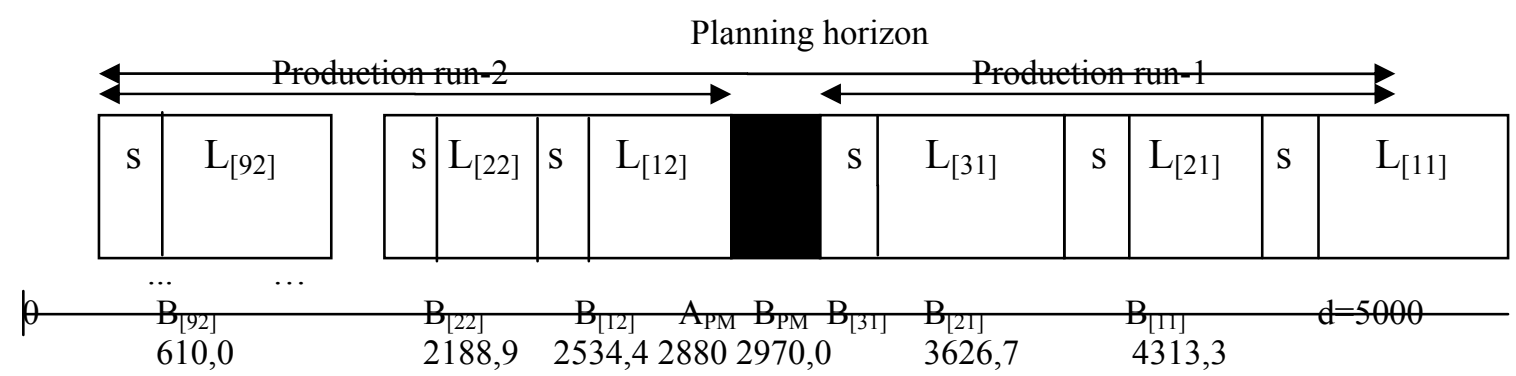

: Unavailability machine

Figure 2 The Best Solution for the Example of the Problem 


\section{CONCLUSIONS}

The model integrates batch scheduling and maintenance scheduling to the total actual flow time. The problem in the model is divided into two, i. e., to determine batch production schedule and the second is to determine the best schedule for preventive maintenance that minimizes total actual flow time. The solution is to accommodate a trade off in the following two things. An increase in the number of the batch (length of production run) up to a certain limit will minimize the total actual flow time. Meanwhile, an increase in the length of production run will implicate an increase in the number of PM.

This research can be continued by including aspects of deterioration of the machine by including the shifting of the process from in-control state to out-of-control state that follows a function of increasing failure rate Weibull, and then calculate the number of corrective maintenance to minimize the total actual flow time.

\section{REFERENCES}

Ben-Daya, M. \& Noman, S. A. (2006). Lot sizing, preventive maintenance and warranty decisions for imperfect production systems. Journal of Quality in Maintenance Engineering, 12(1), 68-80.

Chelbi, A., Rezg, N., \& Radhoui, M. (2008). Simultaneous determination of production lot size and preventive maintenance schedule forunreliable production system. Journal of Quality in Maintenance Engineering, 14(2), 161-176.

El-Ferric, S., \& Ben-Daya, M. (2010). Integrated Production Maintenance Model under Imperfect Age-Based Maintenance Policy and Non-Negligible Maintenace Times. Asia-Pacific Journal of Operational Research, 27(4), 539-558.

Halim, A. H. (1993). Batch Scheduling for Production Systems under Just in Time Environment, Doctorate Disertation. University Osaka Perfecture, Japan.

Lee, H. L., \& Rosenblat, M. J. (1987). Simultaneous Determination of Production Cycle and Inspection Schedules in a Production System. Management Science, 33, 1125-1136.

Lin, L. C., \& Hou, K. L. (2005). EMQ Model with Maintenance Actions for DeterioratingProduction System. Information and Management Sciences, 16(1), 53-65.

Makhdoum, M. A. A. (1996). Integrated production, quality and maintenance models under various preventive maintenance policies. ProQuest Dissertation and Thesis.

Tseng, S.T. (1996). Optimal Preventive Maintenance Policy for Deteriorating Production Systems. IIE Transactions, 28, 687-694.

Wang, C. H., \& Sheu, S. H. (2001). Simultaneous Determination of the Optimal Production Inventory and Product Inspection Policies for a Deteriorating Production System. Computers \& Operations Research, 28, 1093-1110.

Zahedi. (2013). Model Penjadwalan Batch dengan Waktu Ketaktersediaan Mesin sebagai Proporsi Production Run dengan Kriteria Minimasi Total Actual Flow Time. Jurnal MatStat, 13(2), 112-120. 